\title{
Os 12 eixos da comunicação combinada para a saúde pública municipal: uma proposta
}

\author{
The 12 axes of the combined communication for municipal public health: \\ a proposal
}

\section{Los 12 ejes de la comunicación combinada para la salud pública municipal: una propuesta}

\author{
Arquimedes Pessoni $i^{1, a}$ \\ arquimedes.pessoni@uol.com.br | https://orcid.org/0000-0003-1050-3405 \\ Thiago Passaro ${ }^{1, b}$ \\ passaro.thiago@gmail.com | https://orcid.org/o0oo-0003-1340-9879 \\ ${ }^{1}$ Universidade Municipal de São Caetano do Sul. São Caetano do Sul, SP, Brasil. \\ a Doutorado em Comunicação Social pela Universidade Metodista de São Paulo. \\ b Mestrado em Inovação na Comunicação de Interesse Público pela Universidade Municipal de São Caetano do Sul.
}

\section{RESUMO}

Este artigo apresenta os resultados inéditos de uma pesquisa de mestrado (2017-2019) sobre a inovação na gestão da comunicação das Secretarias Municipais de Saúde (SMS). Os métodos utilizados foram revisão de literatura, estudo de caso da SMS de São Paulo - com coleta de documentos, entrevistas semiestruturadas em profundidade com gestores de comunicação e observação participante - e análise de conteúdo. Os resultados mostram que a comunicação integrada, estratégica e multimídia, alinhada aos princípios do Sistema Único de Saúde (SUS), contribui para aumentar a eficácia e a eficiência da comunicação e saúde no nível local. Para isso, as SMS podem fazer uso, com base no contexto local, dos 12 eixos de comunicação propostos pelo estudo, que são: comunicação interna, assessoria de imprensa, cerimonial/eventos, criação/ publicidade, audiovisual, site/portal, redes sociais, aplicativos para dispositivos móveis, jogos, fotografia, parcerias e realidade virtual, realidade aumentada e produções em $360^{\circ}$.

Palavras-chave: Inovação organizacional; Comunicação em saúde; Sistema Único de Saúde; Multimídia; Gestão das tecnologias de informação e comunicação.

\section{ABSTRACT}

This article presents the results of a master's research (2017-2019) on innovation in the communication management of the Municipal Health Departments (SMS). The methods used were the literature review, the SMS case study in São Paulo - with document collection, in-depth semi-structured interviews with communication managers and participant observation - and content analysis. The results show that 
integrated, strategic, and multimedia communication, aligned with the principles of the Unified Health System (SUS), contributes to increase the efficiency and effectiveness of communication and health at the local level. For this, how SMS can use, based on the local context, the 12 communication axes proposed by the study, which are: internal communication, press relations, ceremonial / events, creation / advertising, audiovisual, website / portal, social networks, apps for mobile devices, games, photography, partnerships and virtual reality, augmented reality and $360^{\circ}$ productions.

Keywords: Organizational innovation; Health communication; Unified Health System; Multimedia; Media; Management of information and communication technologies.

\section{RESUMEN}

Este artículo presenta los resultados de una investigación de maestría (2017-2019) sobre innovación en la gestión de la comunicación de los Departamentos Municipales de Salud (SMS). Los métodos utilizados fueron la revisión de la literatura, el estudio de caso de SMS en São Paulo, con recopilación de documentos, entrevistas semiestructuradas en profundidad con gerentes de comunicación y observación participante, y análisis de contenido. Los resultados muestran que la comunicación integrada, estratégica y multimedia, alineada con los principios del Sistema Único de Salud (SUS), contribuye a aumentar la eficiencia y la eficacia de la comunicación y la salud a nivel local. Para esto, cómo pueden usar los SMS, en función del contexto local, los 12 ejes de comunicación propuestos por el estudio, que son: comunicación interna, relaciones con la prensa, ceremoniales/eventos, creación/publicidad, audiovisuales, sitio web/portal, redes sociales, aplicaciones para dispositivos móviles, juegos, fotografía, asociaciones y realidad virtual, realidad aumentada y producciones $360^{\circ}$.

Palabras clave: Innovación organizacional; Comunicación de salud; Sistema único de Salud; Multimedia; Gestión de tecnologías de información y comunicación.

Contribuição dos autores:

Concepção e desenho do estudo: Arquimedes Pessoni e Thiago Passaro.

Análise e interpretação dos dados: Thiago Passaro.

Redação do manuscrito: Thiago Passaro.

Revisão crítica do conteúdo intelectual: Arquimedes Pessoni.

Declaração de conflito de interesses: não há.

Fontes de financiamento: não houve.

Considerações éticas: $\mathrm{O}$ artigo é fruto de uma pesquisa que precisou ser analisada e aprovada pelos Comitês de Ética da Universidade Municipal de São Caetano do Sul e da Secretaria Municipal da Saúde de São Paulo. A aprovação se deu primeiro no Comitê de Ética da USCS (número dos pareceres de aprovação da pesquisa e emenda do estudo pelo do CEP da USCS: 2.993.624 e 3.038.916, respectivamente) e depois no da SMS (número dos pareceres de aprovação da pesquisa e emenda do estudo pelo do CEP da SMS-SP: 3.045.344 e 3.048.139, respectivamente).

Agradecimentos/Contribuições adicionais: não há.

Histórico do artigo: submetido: 17 mar. 2020. | aceito: 4 ago. 2020 | publicado: 22 mar. 2021.

Apresentação anterior: não há.

Licença CC BY-NC atribuição não comercial. Com essa licença é permitido acessar, baixar (download), copiar, imprimir, compartilhar, reutilizar e distribuir os artigos, desde que para uso não comercial e com a citação da fonte, conferindo os devidos créditos de autoria e menção à Reciis. Nesses casos, nenhuma permissão é necessária por parte dos autores ou dos editores. 


\section{INTRODUÇÃO}

O Sistema Único de Saúde (SUS) já tem mais de 30 anos de existência. Foi a partir de 1988, com a criação da Constituição Federal Brasileira, que a máxima da saúde como "um direito de todos e dever do Estado" (BRASIL, 1988) entrou para a história. Dois anos mais tarde, a Lei no ${ }^{\circ}$ 8.080, mais conhecida como Lei Orgânica da Saúde, regulamentou "as ações e serviços de saúde" em todo o país, bem como "as condições para a promoção, proteção e recuperação da saúde, a organização e o funcionamento dos serviços correspondentes" (BRASIL, 1990).

Antes do SUS, os órgãos públicos de saúde, como o Ministério e as Secretarias de Estado e Municipais, tinham uma atuação muito limitada, realizando apenas atividades de promoção de saúde e prevenção de doenças (CONASS, 2003), com destaques para as campanhas de vacinação e controle de endemias (SOUZA, 2002). Segundo o autor, "A grande atuação do poder público nessa área [assistência médico-hospitalar] se dava através do (...) Instituto Nacional de Assistência Médica da Previdência Social (INAMPS), (...) [que] beneficiava apenas os trabalhadores da economia formal, com 'carteira assinada', e seus dependentes" (2002, p. 11-12).

Isso significa que a saúde até 1988 não era universal, como hoje preveem os princípios doutrinários do Sistema Único de Saúde, que incluem ainda a integralidade, a equidade e a descentralização, hierarquização e a participação social, sendo os três últimos pertencentes aos princípios organizativos (BRASIL, 2000; ARAÚJO; CARDOSO; MURTINHO, 2009). Esses preceitos institucionais são fundamentais para o norteamento do sistema (SILVA; ROCHA, 2013), bem como para o trabalho dos gestores e colaboradores.

A comunicação pode colaborar para que todos esses princípios se tornem práticas cotidianas (SILVA; ROCHA, 2013), além de ser um elemento-chave para efetivar a promoção da saúde e políticas públicas nesta área (BELTRÁN SALMÓN, 2001). Segundo defende Araújo (2017, p. 11): "Não se atinge a universalidade, não se pratica a equidade, não se constitui a integralidade. Não se tem saúde sem comunicação. Comunicação é Saúde”.

A informação também é dos princípios do SUS, como é possível observar nos incisos V e VI, do artigo $7^{\circ}$, da Lei no. 8.080: "direito à informação, às pessoas assistidas, sobre sua saúde" e "divulgação de informações quanto ao potencial dos serviços de saúde e a sua utilização pelo usuário”, respectivamente (BRASIL, 1990). Para além da saúde, conforme a Constituição Federal (BRASIL, 1988), é obrigação do governo como um todo criar, manter e aperfeiçoar constantemente os canais oficiais de comunicação com a população.

No nível municipal, por estar mais próximo da população, esse dever do poder público se potencializa, já que, segundo Oliveira (2015, p. 47) “[...] a comunicação deverá atender às necessidades das camadas mais pobres e, também, das camadas mais ricas. Falaremos com o morador das áreas periféricas e com aqueles que vivem nos condomínios urbanos, sendo que ambos têm o direito a receber informações do governo".

Apesar disso, uma pesquisa realizada pela Fundação Oswaldo Cruz (Fiocruz) mostrou que a comunicação em saúde é mal gerenciada pelo poder público, ao constatar, por exemplo, que (I) as estruturas de comunicação são frágeis, (II) os setores de comunicação operam como um 'balcão' para atendimento de demandas pontuais, (III) o poder normalmente é centralizado em um gestor, o que gera pouca autonomia para a área de comunicação, e (IV) há uma concentração do trabalho em atividades de assessoria de imprensa, focada em um relacionamento com a mídia para promoção da gestão; para a (V) população são destinadas apenas as tradicionais práticas transferenciais de informação e ações sazonais. Os resultados apontaram também (VI) falta de conhecimento das entidades do público-alvo - o que leva a abordagens padronizadas e até estereotipadas -, (VII) ausência de investimento na atualização da equipe - profissionais que muitas vezes não conhecem a estrutura e os protocolos da saúde pública -, (VIII) dificuldades de apropriação das 
modalidades mais interativas, como a internet, e (IX) inexistência de um plano, política ou planejamento de comunicação documentado (ARAÚJO; CARDOSO; MURTINHO, 2009).

Além de todos os problemas elencados, adiciona-se ainda a não utilização de meios institucionais de comunicação, como site próprio, TV corporativa, criação publicitária, redes sociais e eventos - ou se criados, colocados em segundo plano, sem compromisso de veicular periodicamente informações de interesse público e empregados sem estratégias multimídia e integradas.

Tendo em vista todos esses aspectos, esta pesquisa visa a identificar como as Secretarias Municipais da Saúde (SMS), a partir de um estudo de caso da SMS de São Paulo, podem utilizar a comunicação para atingir com mais eficiência e eficácia seus públicos, em especial os cidadãos, com foco no interesse público.

E aqui vale abrir um parêntese para entender os conceitos de eficácia e eficiência. De acordo com o Dicionário Michaelis, eficiência é definida como a "capacidade de realizar bem um trabalho ou desempenhar adequadamente uma função; aptidão, capacidade, competência” (EFICIÊNCIA, 2020). Já eficácia é a "qualidade do que produz o resultado esperado; infalibilidade, segurança, validez" (EFICÁCIA, 2020). Ou seja, enquanto o primeiro está ligado ao processo, o segundo se relaciona com os resultados. Waltter Júnior (2014) destaca que "realizar uma tarefa da maneira adequada aumenta consideravelmente a chance de alcançarmos o resultado pretendido, de forma que a busca pela qualidade tanto na execução como no resultado deve ser uma constante. Assim, embora diferentes, ambos os conceitos devem estar presentes".

Fechado o parêntese, destaca-se ainda que os resultados aqui apresentados são inéditos e fruto de uma pesquisa empírica de mestrado desenvolvida entre 2017 e 2019 na Universidade Municipal de São Caetano do Sul (USCS).

\section{REFERENCIAL TEÓRICO}

A comunicação se consolidou ao longo dos anos como um processo estratégico para a saúde, contribuindo efetivamente para a melhoria da qualidade de vida da população. Segundo Schiavo (2007, p. 7)

A comunicação e saúde é uma abordagem multifacetada e multidisciplinar para alcançar diferentes públicos e compartilhar informações relacionadas à saúde, com o objetivo de influenciar, engajar e promover suporte a indivíduos, comunidades, profissionais de saúde, grupos especiais, formuladores de políticas e o público para defender, introduzir, adotar ou sustentar um comportamento, prática ou política que por fim melhorará os resultados de saúde.

Para atingir esse objetivo, Logullo (2001) aponta como caminho o planejamento da comunicação e saúde $(C \& S)^{i}$ para além das demandas diárias e ainda cita uma série de veículos que podem ser utilizados para o compartilhamento das mensagens. Tóth e Laro (2009) complementam que se faz necessário não só o acesso à informação, mas também o uso integrado de diversas estratégias, como a comunicação interpessoal e a participação das comunidades locais. Nesse sentido, campanhas de comunicação e saúde que justamente combinam diversas estratégias, se comparadas àquelas que usaram um só recurso, têm um maior impacto em melhorar os comportamentos de saúde (ROBINSON, 2014).

O avanço das Tecnologias de Informação e Comunicação (TIC) criou uma "variedade de instrumentos e ações disponíveis, envolvendo veículos impressos e eletrônicos, mídias sociais, agências de notícias, reportagens, entrevistas etc." (KUNSCH, 2013, p. 11). Esses diversos meios existentes possuem potencialidades, ferramentas, recursos, linguagens e formatos próprios, com ethos específicos e relações

i Cabe fazer uma observação quanto ao uso do termo 'comunicação e saúde'. Assim como Azevedo (2012) optou em um estudo, este artigo não entra no debate semântico quanto à tradução de 'health communication', que poderia ser entendido como ‘comunicação e saúde', 'comunicação em saúde', 'comunicação na saúde', 'comunicação para saúde’ ou 'comunicação da saúde'. Há trabalhos acadêmicos que fazem as devidas distinções, mas preferiu-se o uso da conjunção 'e’ por acentuar a articulação (EMERICH; CAVACA; GENTILLI; EMMERICH, 2016) e significar a união de dois campos que são multi e interdisciplinares, além de compostos (ALCALAY, 1999; PESSONI, 2007; SCHIAVO, 2007; ARAÚJO; CARDOSO; MURTINHO, 2009). 
singulares com públicos e mercados diversos (XAVIER, 2006), o que também implica diferentes maneiras de codificação (MALIZIA, 2012). Isso porque, como McLuhan (1979) já dizia, o meio é a mensagem e, portanto, cada um dos canais disponíveis, desde um simples folheto até produtos em realidades virtual e aumentada, impactará diretamente e de formas variadas na produção e recepção da comunicação que se pretende fazer.

Tanvatanakul, Amado e Saowakonthab (2007) realizaram um estudo justamente para avaliar a interferência de determinados tipos de meios de comunicação nos participantes. A pesquisa mostrou que o uso de diferentes mídias correspondeu às preferências de consumo de cada segmento populacional e que isso maximiza os esforços de promover informações, atitudes e comportamentos positivos de saúde.

É por isso que a comunicação e saúde deve combinar “ferramentas inovadoras com técnicas einstrumentos tradicionais (...). Dessa forma, atingimos públicos diferenciados através de dinâmicas variadas" (RUÃO, 2013, p. 21). Focar em poucos, ou até mesmo só um meio, é limitar a abrangência e a eficácia da C\&S.

Rosa e Raia (2010) concluíram exatamente isso ao avaliar a comunicação impressa de uma Unidade Básica de Saúde (UBS) da periferia da cidade de São Paulo com mulheres acima dos 60 anos. As autoras observaram que o cartaz era o único meio de divulgação e que isso implicava resultados insignificantes: "Era óbvio que boa parte das usuárias idosas não tomava conhecimento, pelo simples motivo de que não liam o que era anunciado de forma escrita, por problema de visão não corrigido ou por analfabetismo" (2010, p. 76). E se a mesma mensagem tivesse sido adaptada para outro meio, como a TV corporativa, que pode fazer uso de imagens e do áudio, sem a necessidade do texto? E se a comunicação tivesse sido construída em conjunto com o público-alvo? O impacto poderia ter sido maior e o conteúdo chegado às idosas.

O resultado identificado pelas autoras reforça que nenhum veículo consegue alcançar $100 \%$ da população (LOGULLO, 2001), por isso o uso diversificado dos meios de comunicação é imprescindível quando se objetiva atingir um público mais abrangente (OLIVEIRA, 2015), o que faz todo o sentido para a saúde pública, na qual todos estão inseridos.

É justamente nessa perspectiva que aqui se compreende o conceito de multimídia, como a "combinação de diferentes meios e veículos que favorecem os objetivos de comunicação, bem como sua cobertura e distribuição de frequência" (MULTIMÍDIA, 2020). Distingue-se, portanto, da definição de multimídia como o conjunto de formatos de comunicação para se contar uma história, disponíveis em um ambiente convergente, normalmente online (MOLONEY, 2014). É o caso, por exemplo, das reportagens especiais produzidas por periódicos, em que se tem um tema central, destrinchado em subtemas, e estes retratados de diferentes formas, como textos, fotos, vídeos e áudios, e veiculados numa mesma página na internet.

O conceito de multimídia usado nesse estudo se aproxima mais de crossmídia e transmídia, sendo o primeiro entendido como a forma de contar uma mesma história em diferentes canais midiáticos, e o segundo um conjunto de histórias, também disponível em múltiplos formatos e mídias, mas que se complementa e está dentro do mesmo universo (WILJER; CATTON, 2003).

Dessa forma, a comunicação multimídia também apresenta como vantagem a flexibilidade, pois permite acessar variados níveis de conhecimento, promove experiências únicas entre pacientes e profissionais da saúde, apresenta conteúdos em diferentes formatos com diferentes perspectivas e customiza as informações para as necessidades dos indivíduos (WILJER; CATTON, 2003).

\section{METODOLOGIA}

A natureza metodológica desta pesquisa são os procedimentos qualitativos, que possuem, entre outras características, uma base de dados formada de texto e imagem, a condição de ser fundamentalmente interpretativos e fazerem o pesquisador ter um raciocínio complexo multifacetado, interativo e simultâneo (CRESWELL, 2007). 
O nível é exploratório, que abrange estudos que "têm como principal finalidade desenvolver, esclarecer e modificar conceitos e ideias, tendo em vista a formulação de problemas mais precisos ou hipóteses pesquisáveis para estudos posteriores" (GIL, 2008, p. 27).

A pesquisa contou com revisão de literatura, com o objetivo de construir um arcabouço teórico sobre o tema. Para isso, foram realizadas duas etapas de buscas de conteúdos científicos: a primeira se subdividiu em dois eixos: 'comunicação e saúde' e 'multimídia', como pode ser visto na seção 'referencial teórico' deste artigo e em parte da 'introdução'; a outra etapa se deu pela pesquisa de cada um dos 12 eixos de comunicação integrantes da mandala da 'comunicação combinada' a ser apresentada nos resultados. Em ambos os casos, a busca dos artigos, documentos e livros foi realizada no Google Acadêmico, sem recorte temporal - uma vez que a restrição de cinco anos anteriores (2014-2019) limitou e muito os resultados de alguns temas - e uso dos descritores: 'comunicação e saúde'; 'multimídia'; 'multimídia AND saúde'; 'comunicação interna'; 'comunicação interna AND saúde'; 'assessoria de imprensa'; 'assessoria de imprensa AND saúde'; 'eventos’; 'eventos AND saúde'; 'publicidade AND saúde'; 'audiovisual'; 'audiovisual AND saúde’; 'site AND saúde’; 'portal AND saúde'; 'redes sociais AND saúde'; 'aplicativos AND saúde', 'jogos AND saúde'; 'fotografia AND saúde'; 'parcerias AND saúde'; 'realidade virtual'; 'realidade aumentada'; 'vídeos 360º', 'realidade virtual AND saúde'; 'realidade aumentada AND saúde'; 'vídeos $360^{\circ}$ AND saúde', bem como suas respectivas traduções para o inglês.

Foram encontrados 483 conteúdos disponibilizados apenas nas duas primeiras páginas de busca. Desse total, os autores leram os respectivos títulos e resumos para incluir apenas aqueles trabalhos que tinham aderência à proposta da pesquisa. Além disso, acrescentou-se também textos que foram citados nos próprios artigos e que os pesquisadores julgaram interessantes para compor o estudo. Por fim, foram incluídos conteúdos científicos indicados pelo orientador da pesquisa e que não estavam nos resultados de busca no Google Acadêmico. Ao total, a dissertação que deu origem a esse artigo contou com 221 textos acadêmicos referenciados, parte deles utilizada neste trabalho.

Durante a revisão de literatura, identificou-se uma lacuna de investigações sobre a comunicação e saúde no nível municipal. Optou-se, então, pela realização de um estudo de caso da Assessoria de Comunicação (Ascom) da Secretaria Municipal da Saúde de São Paulo. Este delineamento permite uma investigação empírica de "um fenômeno contemporâneo dentro do seu contexto da vida real, especialmente quando os limites entre o fenômeno e o contexto não estão claramente definidos” (YIN, 2010, p. 32).

A escolha da Ascom para análise se deu pelo fato de o objeto de estudo ser municipal, o que atendia ao foco desta pesquisa, que pretendia estudar a comunicação e saúde pública no primeiro nível das três esferas de poder. Além disso, raramente se identificou na revisão de literatura conteúdos que analisassem o trabalho comunicativo em saúde desenvolvido por SMS; o foco, normalmente, fica para as campanhas ministeriais e até internacionais. Avaliar e documentar as atividades da Ascom/SMS-SP foi, inclusive, uma forma de contribuir para o preenchimento desta lacuna teórico-referencial. Para finalizar a justificativa, São Paulo foi escolhida por ser a maior metrópole do país e da América Latina em número de habitantes, abrigando diversos serviços de saúde de referência nacional e internacional.

A coleta de dados se deu por meio de documentos de comunicação produzidos pela Secretaria Municipal da Saúde de São Paulo, majoritariamente os materiais digitais e online, como posts nas redes sociais institucionais da pasta. Esses documentos foram selecionados com base nas entrevistas realizadas, que serão explicadas a seguir, já que os entrevistados citavam determinadas postagens ou outros materiais produzidos pela Ascom. A escolha também foi realizada de acordo com os eixos de comunicação e temas abordados no texto, em que se buscou por exemplos nos documentos da SMS. 
Outra forma de coleta de dados foi a realização de entrevistas com os gestores e ex-gestores dos núcleos da Ascom, formada por assessoria de imprensa, criação, cerimonial e eventos, fotografia, redes sociais e portal - essas duas últimas áreas hoje compõem o núcleo de plataformas digitais.

Justamente por conta das entrevistas, esta pesquisa teve que ser analisada e aprovada pelos Comitês de Ética da Universidade Municipal de São Caetano do Sul e da Secretaria Municipal da Saúde de São Paulo.

Para segurança dos participantes, foi exigido que os nomes dos gestores que aceitassem participar do estudo fossem omitidos, substituindo-os, então, pela expressão ‘Gestor de Comunicação’, que não identifica o sexo do entrevistado, com o complemento de um número. A numeração não seguiu uma ordem específica e foi feita de forma aleatória.

A princípio, a proposta metodológica era entrevistar apenas os atuais gestores dos núcleos da Ascom. Porém, durante a tramitação da pesquisa nos Comitês de Ética, que durou cerca de cinco meses, houve trocas de lideranças nas áreas, com a saída de pessoas que tinham muito a contribuir com o estudo. Além disso, colaboradores que já tinham deixado a comunicação da pasta de saúde paulistana também poderiam acrescentar pontos de vista interessantes. A inclusão dos ex-gestores potencializou ainda o sigilo, pois, em nenhum momento da pesquisa foi identificado se o entrevistado ainda é ou já foi colaborador da Ascom. Por isso, decidiu-se, então, solicitar aos comitês uma emenda ao estudo, para incluir esses potenciais participantes.

Após a pesquisa e a emenda terem sido aprovadas pelos comitês, ainda houve trocas de gestores na Ascom. Se essa alta rotatividade se mantivesse, as entrevistas seriam praticamente contínuas, o que comprometeria a finalização deste estudo. Foi preciso, então, propor um recorte: as entrevistas seriam com os atuais gestores na data de aprovação da emenda pelo Comitê de Ética da SMS-SP, na última etapa de assentimento, que aconteceu em 30 de novembro de 2018. É possível, portanto, que gestores à época das entrevistas estivessem ocupando a liderança do núcleo e atualmente não serem mais pertencentes ao quadro de colaboradores da SMS.

Outro ponto é que se fez necessário delimitar até quanto tempo no passado a pesquisa iria. Primeiramente, sugeriu-se entrevistas com os gestores apenas dos núcleos que existiam na data de aprovação da emenda pela SMS-SP, o que excluiu, portanto, a TV corporativa, que tinha sido extinta em julho de 2017. Quanto aos ex-gestores, o limite foi a data de entrada na Ascom para não antes de janeiro de 2013, mês de início de uma nova gestão na Prefeitura de São Paulo, que marcou, também, a entrada de um dos autores na equipe de comunicação da pasta. Isso porque essa pesquisa também faz uso da observação participante, detalhada mais à frente.

Com isso, 15 pessoas foram identificadas como pertencentes ao critério de inclusão da pesquisa. Essa seleção intencional de amostra permitiu um recorte específico dos entrevistados para uma melhor contribuição ao estudo.c

As entrevistas foram agendadas previamente por contato pessoal ou mesmo pelo aplicativo de mensagens WhatsApp. Realizadas entre dezembro de 2018 e abril de 2019, 12 conversas foram feitas pessoalmente, em locais de escolha dos entrevistados e gravadas em áudio. Todas as conversas foram transcritas na íntegra. É importante destacar que o roteiro de perguntas era padrão para todos os entrevistados; apenas no final havia uma segmentação de questões para os gestores de cada área.

Em razão à falta de disponibilidade dos participantes, dois entrevistados solicitaram responder as perguntas por e-mail, a partir do mesmo roteiro de perguntas, que foi adaptado para facilitar a autoaplicação, o que se aproxima da técnica de questionário, em que as perguntas são totalmente estruturadas e respondidas pelo próprio participante (GIL, 2002). Ainda assim, um dos entrevistados não entregou as questões respondidas a tempo do término da pesquisa. Um potencial participante também não teve agenda 
para a entrevista presencial e não aceitou responder o questionário por e-mail. Totalizou-se, dessa forma, um universo de 13 gestores e ex-gestores entrevistados.

Como já adiantado, este estudo também fez uso da observação participante, "na qual você não é apenas um observador passivo. Em vez disso, você pode assumir uma variedade de funções dentro de um estudo de caso e pode, de fato, participar dos eventos que estão sendo estudados" (YIN, 2010, p. 116). A participação se dá pelo fato de um dos autores ser coordenador de comunicação da Coordenadoria de Infecções Sexualmente Transmissíveis (IST)/Aids da Cidade da São Paulo, órgão da SMS, e já ter feito parte do quadro de colaboradores da extinta TV corporativa da pasta municipal de saúde, o que o torna muito próximo das atividades realizadas pela Ascom, já que ambos os setores se subordinam ou se subordinavam hierarquicamente à assessoria.

Os dados coletados foram analisados pelos seus conteúdos, método definido por Bardin (1995, p. 42) como

um conjunto de técnicas de análise das comunicações visando a obter, por procedimentos sistemáticos e objetivos de descrição do conteúdo das mensagens, indicadores (quantitativos ou não) que permitam a inferência de conhecimentos relativos às condições de produção/recepção (variáveis inferidas) destas mensagens.

Como prevê a análise de conteúdo, as informações como um todo devem ser divididas em categorias visando a objetivar e racionalizar o estudo, ao "introduzir uma ordem, segundo certos critérios, na desordem aparente" (BARDIN, 1995, p. 37)). Esses critérios se baseiam na "frequência de presença (ou de ausência) de itens de sentido" (BARDIN, 1995, p. 37)

No caso dessa pesquisa, as categorias emergiram do próprio estudo de caso, a partir dos núcleos da Ascom (assessoria de imprensa, criação/publicidade, fotografia, redes sociais, cerimonial/eventos e site/portal), em que os entrevistados foram divididos pelos setores que gerenciam ou gerenciaram. Outras categorias também foram definidas com base na revisão de literatura e ainda na experiência empírica de um dos autores, já que não eram contempladas na Assessoria de Comunicação da SMS-SP (comunicação interna, aplicativos para dispositivos móveis, parcerias, jogos, audiovisual e realidade virtual, realidade aumentada e produções em $360^{\circ}$ ), mas se mostraram de fundamental importância para uma maior eficiência e eficácia da comunicação e saúde. É dessa forma que surgem os 12 eixos de comunicação, que serão explicados a seguir.

\section{RESULTADOS}

Assim como a revisão de literatura apontou, 100\% dos gestores e ex-gestores da Ascom entrevistados também reforçaram a importância do uso de estratégias de comunicação integradas e multimídia para aumentar a eficácia e eficiência da C\&S nas SMS, como pode ser visto no depoimento abaixo:

"[...] então só assessoria de imprensa funciona? Não. Então tive que ter uma comunicação que chegasse por todos os canais. [...] Então, era TV que está passando uma campanha de não falte na UBS, redes sociais precisa tá falando disso, portal tem que trazer uma matéria que fale dessa importância, vamos tentar uma pauta sobre como é a perda primária na rede, como isso impacta o serviço, criação vai fazer campanha pra pôr na... porque a pessoa tinha que olhar a TV, ver o celular dela, ouvir no rádio pra que ela comece a perceber que é um todo" (GESTOR DE COMUNICAÇÃO 11, 2019).

É o que também avalia outro gestor:

"[...] eu vejo da seguinte forma: se eu estou trabalhando um material com imprensa para falar de dengue, eu não posso ter minhas redes sociais falando de HPV. Vamos todo mundo falar da mesma coisa. E coordenar isso com criação, claro. E o secretário estar envolvido em eventos relacionados ao 
tema. Pra mim, tem que ser um pacote de ações, para cada tema ser criado um plano em que englobe todos os núcleos de comunicação" (GESTOR DE COMUNICAÇÃO 7, 2019).

Para o Gestor de Comunicação 6 (2018),

"você não pode pensar em comunicação hoje sem pensar em uma comunicação multimídia, sem pensar na mais avançada tecnologia que você possa ter. [...] Tem que integrar tudo.” (GESTOR DE COMUNICAÇÃO 6, 2018).

Apesar de todos os entrevistados ressaltarem a importância dessa visão para a comunicação, especialmente na saúde, foram observados relatos de gestores afirmando que a Ascom falha ao implantar tais estratégias integradas e multimídia.

"Às vezes, a assessoria de imprensa estava soltando um release que a gente não fazia a mínima ideia de que isso ia virar pauta na imprensa." (GESTOR DE COMUNICAÇÃO 8, 2019).

Outro depoimento também ressalta esse problema de comunicação entre a própria equipe:

"E esse negócio eu sentia muito quando tinha as coletivas do prefeito, lá na prefeitura, porque aí chegava a gente do cerimonial, aí chegava depois o pessoal das redes, sendo que podia ir todo mundo junto, aí depois chegava fotógrafo, então assim, na hora todo mundo se encontrava ali, mas estava todo mundo saindo do mesmo lugar, e ninguém sabia que estava indo todo mundo pro mesmo lugar. Tinha muito disso, mas por falta de conversa mesmo.” (GESTOR DE COMUNICAÇÃO 5, 2018).

É evidente que essa falta de comunicação acaba interferindo nos próprios fluxos internos da Ascom, na qualidade do produto e até no conteúdo que é oferecido ao cidadão, como avalia um profissional:

"Uma equipe que não tem essa integração está fadada ao fracasso, porque todas as áreas têm que conversar entre si e nem só na questão de produção de post, porque, assim, redes sociais pegam muito essa questão de posts do que assessoria de imprensa responde, enfim. Mas também ali uns discursos dessa forma, já que não tem nada documentado pelo menos, dialogando com as áreas. A gente consegue alinhar um discurso, consegue estar a par do que o outro está produzindo e está resguardado também. Enfim, eu não sei, mas é imprescindível que essas áreas concordem entre si." (GESTOR DE COMUNICAÇÃO 4, 2019).

Ressaltada a importância de se trabalhar com uma comunicação integrada e multimídia na saúde pública, tanto do ponto de vista dos autores, quanto dos entrevistados, chega a hora de apresentar, então, quais estratégias de comunicação podem fazer parte dessa visão mais ampla.

Nesse sentido, a pesquisa identificou 12 eixos de comunicação - que são estratégias, mídias e áreas da comunicação - que podem estar à disposição das pastas municipais de saúde para justamente serem implantados ou aperfeiçoados, não de forma individual, mas sim combinados para se complementarem. São eles: comunicação interna, assessoria de imprensa, cerimonial/eventos, criação/publicidade, audiovisual, 
site/portal, redes sociais, aplicativos para dispositivos móveis, jogos, fotografia, parcerias e realidade virtual, realidade aumentada e produções em $360^{\circ}$.

Parte dos eixos correspondem aos seis núcleos existentes da Ascom. A partir dessa perspectiva, esses eixos apresentam um diagnóstico do trabalho de comunicação realizado pelos núcleos da assessoria, bem como indicações de melhor aproveitamento estratégico. Os demais eixos, que não são contemplados na Ascom, foram construídos com base na revisão de literatura, como explicado anteriormente, e servem como sugestão de implantação e implementação pelas Secretarias Municipais de Saúde.

O uso integrado e estratégico desses 12 eixos comunicacionais compõe o que a pesquisa chama de 'comunicação combinada', uma licença poética para o conceito de 'prevenção combinada' ao HIV, que reúne diversas tecnologias de prevenção ao vírus causador da aids para serem utilizadas de acordo com o momento de vida e necessidades dos sujeitos, o que gera mais autonomia para os cidadãos (BRASIL, 2017). Para facilitar a visualização de todas essas formas de prevenção ao HIV, o Ministério da Saúde criou uma mandala, que também serviu de inspiração para agrupar ilustrativamente os 12 eixos de comunicação apresentados (Figura 1).

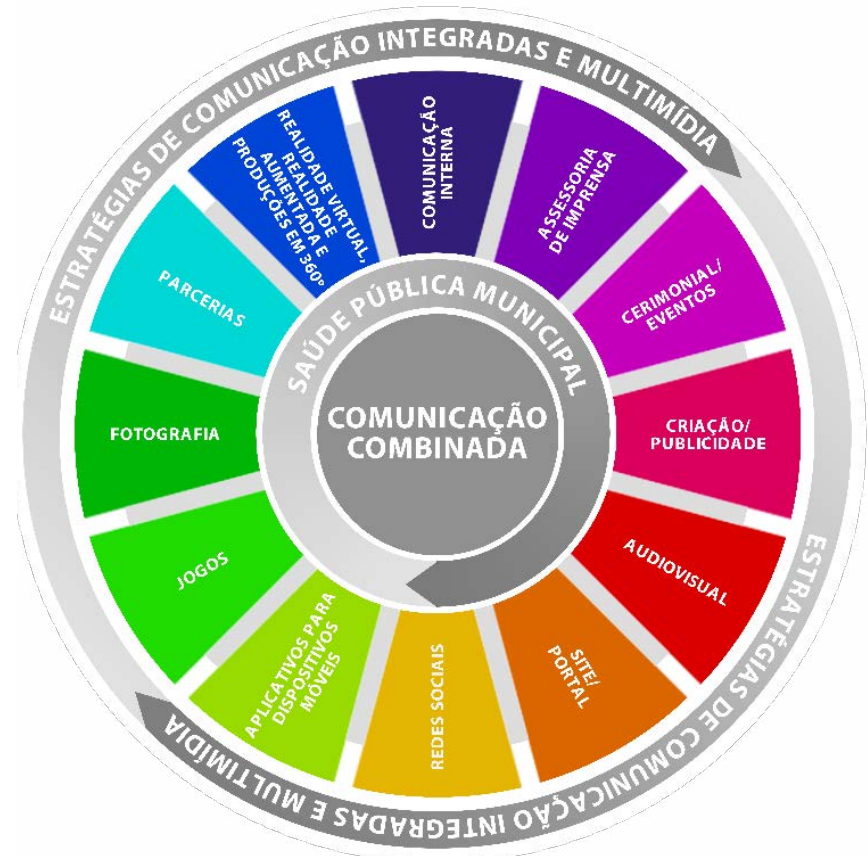

Figura 1 - Representação ilustrativa da mandala dos 12 eixos da Comunicação Combinada Fonte: Passaro (2019).

De forma bem breve, a comunicação interna visa a promover um relacionamento com os colaboradores, os primeiros comunicadores da instituição; é muito mais do que só informar o que a pasta tem feito; é abrir canais de diálogo para construção conjunta e aperfeiçoamento constante da comunicação, além de promover uma comunicação interpessoal mais eficaz e eficiente com os públicos-finais.

Apesar de todas as vantagens e possibilidades da comunicação interna, praticamente todos os gestores entrevistados afirmaram que a SMS-SP não possui estratégias de comunicação para o público interno da pasta ou se existentes, falhas. O órgão municipal paulistano se limita a enviar e-mails para todos os colaboradores, com convites para eventos e cursos, boletins informativos e notícias que possam ser de interesse dos funcionários.

O Gestor de Comunicação 10 (2019) afirmou, no entanto, que cerca de 11 mil Agentes Comunitários de Saúde, por exemplo, não têm acesso ao e-mail institucional, o que prejudica a comunicação interna entre a SMS e os colaboradores. É por isso que o Gestor de Comunicação 12 (2019) defende versões impressas dos boletins. 
O segundo eixo trata da assessoria de imprensa, que é fundamental para que os comunicadores de saúde orientem o jornalista sobre a saúde pública e os temas específicos que a área possui, bem como para prestar serviços aos cidadãos por meio da mídia, que tem caráter de divulgação gratuita e ainda é acrescida de credibilidade jornalística. Pela sua importância estratégica e também pelo alto volume de demandas que a SMS-SP recebe diariamente, o núcleo de assessoria de imprensa é o que concentra o maior número de profissionais na Ascom (26,9\%), seguido pelo de criação (23\%) e redes sociais (19,2\%). Com exceção do setor administrativo, que não é considerado um núcleo, fotografia $(3,8 \%)$ e portal $(7,6 \%)$, por outro lado, são as áreas com menos colaboradores.

Já o eixo cerimonial/eventos tem como objetivo aproximar a secretaria dos munícipes, promover contato com os líderes gestores e permitir a população vivenciar determinada pauta. Na perspectiva da valorização da aproximação que os eventos promovem, o Gestor de Comunicação 5 (2018) faz uma comparação desta estratégia com outros veículos disponíveis na comunicação.

"Na verdade, todo mundo fala com público final. A TV fala com público final, rádio, o cartaz, o banner, mas é pessoa falando com pessoa. É você ali participando. Você se sente participando, sabe? Você olha ali e fala "eu sou parte disso". [...] porque uma coisa é você ver, outra coisa você participar. Porque se for assim, pra que que a gente vai a show por exemplo? Eu assisto na TV, eu vejo o clipe ou só música no Spotify, tipo. Não preciso participar.” (GESTOR DE COMUNICAÇÃO 5, 2018).

Para o Gestor de Comunicação 1 (2018), essa aproximação gerada pelos eventos faz com que a área se torne um setor estratégico.

"[...] você ouve a população, você está perto de todo mundo -, isso é muito importante porque o cerimonialista pode já informar ao secretário: "olha, está acontecendo isso", fazer uma interação com a comunicação de uma forma que já coloque aquela opinião daquela pessoa, já resolva o que ela está pedindo, o que ela está precisando.” (GESTOR DE COMUNICAÇÃO 1, 2018).

A criação/publicidade garante a coordenação da comunicação visual institucional da SMS, criar produtos, peças e campanhas com a linguagem persuasiva típica da publicidade e de definir estratégias de veiculação em mídias e espaços estratégicos, para também se ampliar ou segmentar a audiência. Por conta desse amplo leque de atividades, a área não recebeu um nome mais vinculado à publicidade em si, como explica o Gestor de Comunicação 3 (2019):

“[...] nosso ramo de atuação não se restringe apenas à questão publicitária da secretaria ou das ações, enfim, da secretaria como instituição, das ações como produto. A gente tem produção institucional, que não é campanha, que é muito pesado, campanhas de... ações de endomarketing [...] mas se restringe a ação a esse tipo de segmento, de você promover alguma coisa, sendo que muitas vezes você tá apenas fazendo um desenvolvimento de uma peça institucional... Acho criação mais amplo.” (GESTOR DE COMUNICAÇÃO 3, 2019).

Como visto, uma das responsabilidades do núcleo é a gestão da comunicação visual institucional da SMSSP. Por essa razão, o setor criou manuais de identidade para orientação visual de diversos tipos de serviços de saúde, como UBSs, Centros de Atenção Psicossocial (Caps) e Centro Especializado em Reabilitação 
(CER). Em todos há orientação quanto às cores, imagens, posicionamentos e, claro, de aplicação correta da régua de assinatura da pasta municipal, que é composta pelo logotipo do SUS à direita e o da SMS-SP à esquerda.

"Eu acho que toda empresa tem que ter um programa de identidade visual. [...] através disso, ela consegue expressar os seus valores, a sua essência, o seu conjunto de elementos de interação que criam a sua marca. Marca não é só logotipo, marca é uma condição de todos esses elementos.” (GESTOR DE COMUNICAÇÃO 3, 2019).

O quinto eixo, sobre audiovisual, tem como potencialidade a produção de conteúdos que valorizem o movimento das imagens, a complementariedade da imagem e do som ou mesmo o uso apenas do som. É possível também investir na criação e manutenção de uma TV corporativa para as unidades de saúde, algo que já se mostrou positivo na capital paulista, e criação de podcasts, que estão em alta no momento.

O site/portal são fontes com credibilidade de informação sobre saúde, tanto para os munícipes quanto para os profissionais da área. Essa plataforma deve reunir desde dados técnicos a notícias e serviços, com uma arquitetura de informação que privilegia o cidadão. Recomenda-se ainda que o site/portal utilize os recursos do meio, com complementariedade de conteúdo multimidiáticos, seja acessível para pessoas com deficiência visual e auditiva, com fácil navegação e design agradável. As informações precisam ser coerentes, compreensíveis, objetivas, comprovadas cientificamente, completas e atualizadas.

O Gestor de Comunicação 6 (2018) relatou, porém, que o portal da SMS-SP é um produto comunicacional pouco atrativo, que até recebe um número razoável de visualizações, mas,

"ao comparar o número de acessos que o site tinha como G1, era uma coisa ridícula, porque, na verdade, primeiro que você não tem uma cultura da população de se informar pelos meios de comunicação oficiais [...] e, segundo, [...] porque você não tinha toda a tecnologia, que, por exemplo, o G1 tinha." (GESTOR DE COMUNICAÇÃO 6, 2018).

As redes sociais são o tema do próximo eixo de comunicação. Essas plataformas online são meios interativos com alto poder de democratizar a produção da comunicação, além de aproximar a população das instituições. Elas permitem coletar dados dos usuários, segmentar a comunicação e produzir e veicular uma grande variedade de formatos. As redes sociais contam ainda com recursos estratégicos, como marcação de localização e transmissão ao vivo.

O Facebook, o Twitter, o YouTube e o Instagram, as principais redes sociais globais e brasileiras, possuem características distintas e, por isso, devem ser usadas pelas SMS de forma planejada e integrada. De forma geral, para todas as redes sociais, o Gestor de Comunicação 8 (2019) recomenda:

"alternar tipos de conteúdo, então você posta imagem, posta vídeo, posta link, pra você criar dinamismo na plataforma; [...] interagir com seus usuários, seja na classificação da página, seja nos comentários, seja no inbox; você sempre ter uma acuidade visual, então você sempre postar boas fotos, boas artes, nem que isso signifique você demorar mais duas ou três horas pra você subir; você lançar mão das transmissões ao vivo." (GESTOR DE COMUNICAÇÃO 8, 2019). 
Mas se hoje as redes sociais da Secretaria Municipal da Saúde de São Paulo já estão consolidadas e são até referência para outras instituições (GESTOR DE COMUNICAÇÃO 13, 2018), há quem possa duvidar que até 2015 esses meios ainda não tinham sido utilizados na SMS da capital paulista.

"Não existia uma política de você responder o munícipe em si. Então quando eu fui para lá, eu falei olha, 'se a gente se propõe a abrir uma rede social de um serviço tão sensível quanto é a saúde e não abre um canal para interagir com o munícipe, não faz sentido abrir uma rede social' Põe um cartaz na parede da UBS que vai ter a mesma função.” (GESTOR DE COMUNICAÇÃO 8, 2019).

Observou-se, à época de tratativas da implantação, objeções à ideia por conta de uma série de motivos, como a preocupação com a relação do munícipe com os outros canais de atendimento oficiais da Prefeitura de São Paulo, a exemplo da ouvidoria e do telefone 156, mas, também, com o aumento do número de demandas. O Gestor de Comunicação 8 (2019) relembra e explica:

"Do secretário não, mas das áreas técnicas muita resistência, eles eram absolutamente contra abrir o canal para munícipes, porque ia gerar demandas. [...] Sendo saúde, implica em geração de demanda, de você recorrer às áreas técnicas, de você mandar demandas pras regiões, de você responder por que está faltando fralda? Qual que é a vacina? Fazer a pessoa entender que o cartão do SUS é extremamente importante. Então, você abre uma avenida de questões que você tem que lidar, que quando você tem o inbox fechado, você não lida, mas aí você tem uma falsa sensação de que você está interagindo com os munícipes. [...] mas no começo a gente bancou, mas foi um tiro no escuro, porque poderia dar muito errado.”(GESTOR DE COMUNICAÇÃO 8, 2018).

Apesar de todos esses desafios, é preciso considerar que "desenvolver intervenções de promoção da saúde nessas configurações [ambiente online e interativo], cometer erros e aprender com eles é certamente melhor do que não fazer nada" (GOLD, 2012, tradução nossa). Além do que, é "difícil minimizar o papel que as redes digitais hoje desempenham na vida psíquica, social, cultural, política e econômica” (SANTAELLA, 2013, p. 35). Para uma organização, estar ausente desse processo comunicacional digital e online é como estar incompleta e externa ao mundo atual (MORTARI; SANTOS, 2016).

Dando sequência à mandala da 'comunicação combinada', há os aplicativos para dispositivos móveis, que já se consolidaram como mais uma tecnologia para a comunicação e saúde. O objetivo principal é facilitar o acesso à informação e prestar serviços aos cidadãos, aproveitando os recursos oferecidos pelos aplicativos e pelo próprio dispositivo móvel, como localização (GPS).

No estudo, foi possível identificar uma série de aplicativos utilizados pela SMS-SP, como o Aqui tem remédio e o TáNaMão, que tornaram os conteúdos mais atrativos aos usuários, além de prestarem serviço público. O primeiro informa, por meio de GPS e acesso à internet, em qual unidade de saúde mais próxima o cidadão pode encontrar o medicamento pesquisado na plataforma. O TáNaMão conta com uma calculadora de risco a uma infecção sexualmente transmissível (IST), a partir das informações cedidas pelo usuário, além de também informar, via GPS, os serviços de saúde mais próximos que oferecem testagem rápida para HIV, camisinhas gratuitas, autoteste de HIV etc.

Além disso, os aplicativos também podem ser voltados para os colaboradores da pasta municipal de saúde. A Coordenadoria de IST/Aids, órgão da SMS-SP, por exemplo, conta com dois aplicativos para auxiliar o trabalho dos profissionais da saúde: PEPTec e o TVSP. O primeiro trata das indicações de 
Profilaxia Pós-Exposição (PEP), a partir de protocolos e diretrizes do Ministério da Saúde. Já o segundo se refere à prevenção à transmissão vertical do HIV, sífilis e hepatites virais.

Os jogos, nono eixo, embora encarados pelo senso comum como apenas um meio de entretenimento, também podem ser fonte de conhecimento de saúde, contando ainda com o benefício da ludicidade típica dessas plataformas, dos tradicionais tabuleiros aos digitais, voltados para computador, consoles e aplicativos. Há a vantagem ainda de tanto o público interno quanto os cidadãos serem beneficiados com os jogos.

A fotografia visa a registrar momentos, passar mensagens visuais e complementar conteúdos. É um núcleo fundamental para os demais, sendo muitas vezes o produto ou o material bruto de um trabalho de comunicação.

Já as parcerias potencializam o trabalho de comunicação, ao promoverem a articulação da instituição com atores centrais da sociedade, a depender dos objetivos traçados. Essas parcerias são fundamentais para se ampliar as atividades de saúde e de comunicação e até para otimização dos recursos humanos e financeiros da SMS. A articulação deve, inclusive, acontecer entre órgãos do poder público, sejam do nível municipal, estadual ou federal.

E para finalizar a mandala, temos as realidades virtual e aumentada, além das produções em $360^{\circ}$, que são tecnologias em que o consumo tem crescido nos últimos anos e que podem ser mais uma mídia para comunicar saúde, aproveitando a imersão proporcionada por esses meios.

\section{DISCUSSÃO E CONCLUSÕES}

A partir da metodologia usada nesta pesquisa, é possível afirmar que as SMS devem fazer uso de uma comunicação estratégica, integrada e multimídia, guiada pelos princípios do SUS para atingir com mais eficiência e eficácia os públicos. Uma comunicação integrada e multimídia utiliza diferentes estratégias, meios e áreas da própria comunicação, aproveitando os recursos e as potencialidades de cada, para obter resultados mais eficientes e eficazes ao ampliar a abrangência e ser mais assertiva. Para a saúde pública, portanto, os 12 eixos são fundamentais.

A importância da integração das estratégias de comunicação foi ressaltada, tanto por todos os gestores entrevistados quanto pela revisão de literatura. A proposta foi que as entrevistas complementassem a discussão teórica, suprindo, inclusive, uma lacuna bibliográfica sobre a comunicação na saúde pública municipal. É possível observar ora concordância ora discordância entre o que os autores preconizam ou afirmam com a realidade trazida pelos gestores e ex-gestores da Ascom. Acredita-se que esse intercâmbio contribua para o enriquecimento da pesquisa, unindo a prática - que nem sempre está correta, mas que pode trazer um pouco mais de vivência aos conceitos - com as teorias.

Este estudo não teve a pretensão de criar um modelo normativo e nem um protocolo padrão para todas as SMS, pois cada pasta municipal tem sua(s) realidade(s). O que faz sentido para todas é o uso integrado das estratégias, das diferentes mídias e das áreas de comunicação. Dessa forma, é fundamental que as SMS coloquem o cidadão em foco, "valorizando aspectos de sua cultura, as relações de gênero e os diferentes níveis socioeconômicos e políticos" (PEREIRA; VIEIRA; AMÂNCIO FILHO, 2011, p. 28). Utilizar um site institucional ou desenvolver aplicativos para dispositivos móveis conectados na web, por exemplo, pode fazer todo o sentido para a Secretaria Municipal da Saúde de São Caetano do Sul (SP), a cidade mais conectada à internet do Brasil (FUNDAÇÃO GETULIO VARGAS, 2012), mas ser totalmente irrealista para a SMS de Aroeiras (PI), em que o acesso online é nulo (FUNDAÇÃO GETULIO VARGAS, 2012).

É por isso que a pesquisa não propôs a aplicação dos 12 eixos de comunicação numa determinada localidade, como a cidade de São Paulo, já que essa será justamente uma tarefa de cada pasta municipal, a partir dos contextos locais, públicos específicos, recursos (técnicos, financeiros e humanos) disponíveis etc. 
Não se objetivou ainda abordar conteúdos e menos ainda fazer uma avaliação da recepção dos produtos comunicacionais pela população.

Todos esses temas, inclusive, são recomendados para serem estudados e aprofundados em outras investigações. É possível ainda fazer um levantamento sobre esses aspectos e também sobre a produção da comunicação do ponto de vista da integralidade e multimidialidade em outros campos de atuação, além de diferentes cidades, estados e até no âmbito federal. Isso porque, acredita-se que uma comunicação estratégica, integrada e multimídia vá para além da saúde e valha também para todas as outras pastas, inclusive hierarquias superiores, quiçá para a área privada.

\section{REFERÊNCIAS}

ALCALAY, Rina. La comunicación para la salud como disciplina en las universidades estadounidenses. Pan American Journal of Public Health, Washington, DC, v. 5, n. 3, p. 192-196, 1999. Disponível em: https:// scielosp.org/article/rpsp/1999.v5n3/192-196/. Acesso em: 16 mar. 2020.

ARAÚJO, Inesita Soares de. Lugar de fala, interlocução e escuta, pelo qual se possa conhecer, compreender e apoiar as lutas de Comunicação e Saúde. Ensaios \& Diálogos em Saúde Coletiva, Rio de Janeiro, n. 4, p. 11-14, 20 jun. 2017. Disponível em: https://www.abrasco.org.br/site/wp-content/uploads/2017/06/comunicacao PDF.pdf. Acesso em 17 mar. 2020.

ARAÚJO, Inesita Soares de; CARDOSO, Janine Miranda; MURTINHO, Rodrigo. Políticas e práticas de comunicação no SUS: mapeamento, diagnóstico e metodologia de avaliação. Rio de Janeiro: Fundação Oswaldo Cruz, 2009. Relatório de pesquisa.

AZEVEDO, Ana Paula Margarido. Jornalismo de saúde: novos rumos, novas literacias. Comunicação e Sociedade, Braga, n. esp, p. 185-197, jan. 2012. DOI: https://doi.org/10.17231/comsoc.23(2012).1363. Disponível em: https://revistacomsoc.pt/index.php/revistacomsoc/article/view/1009. Aceso em: 16 mar. 2020.

BARDIN, Laurence. Análise de conteúdo. São Paulo: Edições 70, 1995.

BELTRÁN SALMÓN, Luis Ramiro. La importancia de la comunicación en la promoción de la salud. In: MELO, José Marques de; EPSTEIN, Isaac; SANCHES, Conceição; BARBOSA, Sérgio. Mídia e Saúde. Adamantina: Unesco, 2001. p. 355-368.

BRASIL. [Constituição (1988)]. Constituição da República Federativa do Brasil. Brasília, DF: Presidência da República, [2020]. Disponível em: http://www.planalto.gov.br/ccivil_03/Constituicao/Constituicao.htm. Acesso em: 17 mar. 2020.

BRASIL. Lei no 8080, de 19 de setembro de 1990. Dispõe sobre as condições para a promoção, proteção e recuperação da saúde, a organização e o funcionamento dos serviços correspondentes e dá outras providências. Diário Oficial da União, Brasília, DF, 20 set. 1990. Disponível em: http://www.planalto.gov.br/ ccivil 03/leis/18080.htm. Acesso em: 29 ago. 2020.

BRASIL. Ministério da Saúde. Secretaria de Vigilância em Saúde. Departamento de Vigilância, Prevenção e Controle das Infecções Sexualmente Transmissíveis, do HIV/Aids e das Hepatites Virais. Diretrizes para organização do CTA no âmbito da Prevenção Combinada e nas Redes de Atenção à Saúde. Brasília, DF: Ministério da Saúde, 2017.

BRASIL. Ministério da Saúde. Secretaria Executiva. Princípios do SUS. Brasília, DF: Ministério da Saúde, 2000. Disponível em: https://bvsms.saude.gov.br/bvs/publicacoes/sus principios.pdf. Acesso em: 17 mar. 2020.

CONSELHO NACIONAL DE SECRETÁRIOS DE SAÚDE (CONASS). Para entender a gestão do sUS. Brasília: CONASS, 2003.

CRESWELL, John W. Projeto de pesquisa: métodos qualitativo, quantitativo e misto. Tradução: Luciana de Oliveira da Rocha. 2. ed. Porto Alegre: Artmed, 2007.

EFICÁCIA. In: MICHAELIS: Dicionário Brasileiro da Língua Portuguesa. São Paulo: Melhoramentos, 2020. Disponível em: http://michaelis.uol.com.br/moderno-portugues/busca/portugues-brasileiro/efic\%C3\%A1cial. Acesso em: 10 mar. 2020. 
EFICIÊNCIA. In: MICHAELIS: Dicionário Brasileiro da Língua Portuguesa. São Paulo: Melhoramentos, 2020. Disponível em: http://michaelis.uol.com.br/moderno-portugues/busca/portugues-brasileiro/efici\%C3\%AAncial. Acesso em: 10 mar. 2020.

EMERICH, Tatiana Breder; CAVACA, Aline Guio; GENTILLI, Victor; EMMERICH, Adauto. Necessidades de saúde e direito à comunicação em tempos de midiatização. Revista Eletrônica de Comunicação Informação e Inovação em Saúde, Rio de Janeiro, v. 10, n. 4, p. 1-12, 2016. DOI: https://doi.org/10.29397/reciis. v10i4.1065. Disponível em: https://www.reciis.icict.fiocruz.br/index.php/reciis/article/view/1065. Acesso em: 16 mar. 2020.

FUNDAÇÃO GETÚLIO VARGAS. Mapa da Inclusão Digital. Rio de Janeiro: FGV, 2012.

GIL, Antonio Carlos. Como elaborar projetos de pesquisa. 4. ed. São Paulo: Atlas, 2002.

GIL, Antonio Carlos. Métodos e técnicas de pesquisa social. 6. ed. São Paulo: Atlas, 2008.

GOLD, Judy et al. Developing health promotion interventions on social networking sites: recommendations from The FaceSpace Projet. Journal of Medical Internet Research, Pittsburgh, v. 14, n.1, e30, 2012. DOI: https://dx.doi.org/10.2196\%2Fjmir.1875. Disponível em: https://www.ncbi.nlm.nih.gov/pmc/articles/ PMC3374544/. Acesso em: 16 mar. 2020.

KUNSCH, Margarida M. Krohling. Comunicação pública: direitos de cidadania, fundamentos e práticas. In: MATOS, Heloiza (org.). Comunicação pública: interlocuções, interlocutores e perspectivas. São Paulo: USP, 2013. p. 13-29.

JÚNIOR, Waltter. Qual a diferença entre eficácia e eficiência?. Estudo Administração, [s. I.], 15 out. 2014. Disponível em: http://www.estudoadministracao.com.br/ler/diferenca-entre-eficiencia-eficacial. Acesso em: 10 mar. 2020.

LOGULLO, Patrícia. Comunicação na Eficácia das Intervenções em Saúde Pública. In: MELO, José Marques de; EPSTEIN, Isaac; SANCHES, Conceição; BARBOSA, Sérgio. Mídia e Saúde. Adamantina: Unesco, 2001. p. 193-197.

MALIZIA, Pierfranco. A "telinha particular": objetivos e funções da Web TV na Comunicação Organizacional: uma resenha dos estudos recentes. Intercom: Revista Brasileira de Ciências da Comunicação, São Paulo, v. 35, n. 2, p. 291-311, jul./dez. 2012. DOI: https://doi.org/10.1590/S1809-58442012000200015. Disponível em: https://www.scielo.br/scielo.php?script=sci arttext\&pid=S1809-58442012000200015\&lng=pt\&tlng=pt. Acesso em: 16 mar. 2020.

MCLUHAN, Marshall. Os meios de comunicação como extensões do homem. 5. ed. São Paulo: Cultrix, 1979.

MOLONEY, Kevin. Multimedia, Crossmedia, Transmedia... What's in a name? In: MOLONEY, Kevin. Blog Transmedia Journalism: porting transmedia storytelling to the news business. [S. I.], 21 abr. 2014. Disponível em: https://transmediajournalism.org/2014/04/21/multimedia-crossmedia-transmedia-whats-in-a-namel. Acesso em: 16 mar. 2020.

MORTARI, Elisangela Carlosso Machado; SANTOS, Suzana Fernandes dos. Monitoramento de redes sociais digitais como estratégia organizacional. Intercom: Revista Brasileira de Ciências da Comunicação, São Paulo, v. 39, n. 1, p. 91-109, 2016. DOI: 10.1590/1809-5844201616. Disponível em: https://www.scielo.br/pdf/interc/ v39n1/1809-5844-interc-39-1-0091.pdf. Acesso em: 16 mar. 2020.

MULTIMÍDIA. In: MICHAELIS: Dicionário Brasileiro da Língua Portuguesa. São Paulo: Melhoramentos, 2020. Disponível em: https://michaelis.uol.com.br/moderno-portugues/busca/portugues-brasileiro/ multim\%C3\%ADdial. Acesso em: 13 mar. 2020.

OLIVEIRA, Celso José de. Planejamento de Comunicação: a comunicação como ferramenta essencial da gestão pública e a elaboração do Plano de Comunicação. In: COSTA, Greiner (org.). Comunicação e gestão pública. Campinas (SP): Alínea, 2015. p. 43-62.

PÁSSARO, Thiago. A comunicação estratégica, integrada e multimídia na saúde pública municipal. 2019. Dissertação (Mestrado Profissional em Inovação na Comunicação de Interesse Público) - Universidade Municipal de São Caetano do Sul, São Caetano do Sul, 2019. 
PEREIRA, Audrey Vidal; VIEIRA, Ana Luiza Stiebler, AMÂNCIO FILHO, Antenor. Grupos de Educação em Saúde: aprendizagem permanente com pessoas soropositivas para o HIV. Trabalho, Educação e Saúde, Rio de Janeiro, v. 9, n. 1, p. 25-41, 2011. DOI: https://doi.org/10.1590/S1981-77462011000100003. Disponível em: http://www.scielo.br/scielo.php?script=sci arttext\&pid=S1981-77462011000100003. Acesso em: 16 mar. 2020

PESSONI, Arquimedes. Comunicação para a Saúde: estado da arte da produção norte-americana.

Comunicação \& Inovação, São Caetano do Sul, v. 8, n. 14, p. 61-64, jan./jun. 2007. Disponível em: http:// seer.uscs.edu.br/index.php/revista comunicacao inovacao/article/view/675/521. Acesso em: 16 mar. 2020.

ROBINSON, Maren N. et al. Mass media health communication campaigns combined with health-related product distribution: a community guide systematic review. American Journal of Preventive Medicine, [s. I.], v. 47, n. 3, p. 360-371, set. 2014. DOI: https://doi.org/10.1016/j.amepre.2014.05.034. Disponível em: https:// www.ajpmonline.org/article/S0749-3797(14)00254-2/fulltext. Acesso em: 16 mar. 2020.

ROSA, Tereza Etsuko da Costa; RAIA, Giuliana Fregonezi. O envelhecimento ativo no SUS: comunicação e produção de (não) sentidos em usuárias idosas de uma UBS. Boletim do Instituto de Saúde, São Paulo, v. 12, n. 1, p. 74-79, 2010. Disponível em: http://docs.bvsalud.org/biblioref/2020/01/1048433/bis-v12n1comunicacao-e-saude-74-79.pdf. Acesso em: 16 mar. 2020.

RUÃO, Teresa. Estratégias de comunicação na saúde - na promoção da igualdade. In: LOPES, Felisbela et al. A saúde em notícia: repensando práticas de comunicação. Braga: Centro de Estudos de Comunicação e Sociedade, 2013. p. 16-26.

SANTAELLA, Lúcia. Intersubjetividade nas redes digitais: repercussões na educação. In: PRIMO, Alex (org.). Interações em rede. Porto Alegre: Sulina, 2013. p. 33-47.

SCHIAVO, Renata. Health communication: from theory to practice. São Francisco: Jossey-Bass, 2007.

SILVA, Vivian Costa da; ROCHA, Cristianne Maria Famer. A Comunicação em Saúde no Sistema Único de Saúde: uma revisão de literatura. 2013. Trabalho de conclusão de curso (Bacharelado em Saúde Coletiva) Universidade Federal do Rio Grande do Sul, Porto Alegre, 2013.

SOUZA, Renilson Rehem. O Sistema Público de Saúde Brasileiro. Brasília, DF: Ministério da Saúde, 2002. Trabalho apresentado no Seminário Internacional Tendências e Desafios dos Sistemas de Saúde nas Américas, 2002, São Paulo.

TANVATANAKUL, Vasuton, AMADO, João; SAOWAKONTHAB, Sastri. Management of communication channels for health information in the community. Health Education Journal, [Londres], v. 66, n. 2, p. 173178, 2007. DOI: https://doi.org/10.1177/0017896907076755. Disponível em: https://journals.sagepub.com/ doi/10.1177/0017896907076755. Acesso em: 16 mar. 2020.

TÓTH, Mariann; LARO, Rodrigo. O potencial limitado das campanhas massivas de comunicação para a transformação de comportamentos sociais. In: PAULINO, Fernando Oliveira (org.). Comunicação e Saúde. Brasília: Casa das Musas: 2009. p. 45-54.

WILJER, David; CATTON, Pam. Multimedia Formats for Patient Education and Health Communication: Does User Preference Matter?. Journal of medical internet research, Pittsburgh, v. 5, n. 3, e19, 2003. DOI: https:// doi.org/10.2196/jmir.5.3.e19. Disponível em: https://www.jmir.org/2003/3/e19/. Acesso em: 15 mar. 2020.

XAVIER, Caco. Mídia e Saúde, Saúde na Mídia. In: SANTOS, Adriana (org.). Caderno Mídia e Saúde Pública. Belo Horizonte: Escola de Saúde Pública, 2006. p. 43-55.

YIN, Robert. Estudo de caso: planejamento e métodos. 4. ed. Porto Alegre: Bookman, 2010. 